Cardiology in the Young (2015), 25, 1214-1217 doi:10.1017/S1047951114001802
(C) Cambridge University Press, 2014. This is an Open Access article, distributed under the terms of the Creative Commons Attribution licence (http://creativecommons. org/licenses/by/3.0/), which permits unrestricted re-use, distribution, and reproduction in any medium, provided the original work is properly cited.

\title{
Maternal hyperoxygenation and foetal cardiac MRI in the assessment of the borderline left ventricle
}

\author{
Sharon Borik, ${ }^{1}$ Christopher K. Macgowan, ${ }^{2}$ Mike Seed ${ }^{1}$ \\ ${ }^{1}$ Department of Pediatrics, Labatt Family Heart Center, Division of Cardiology; ${ }^{2}$ Department of Physiology and \\ Experimental Medicine, The Hospital for Sick Children, University of Toronto School of Medicine, Toronto, \\ Ontario, Canada
}

\begin{abstract}
Using phase-contrast MRI in a foetus with borderline left ventricular hypoplasia at 37 weeks' gestation we showed an increase in pulmonary blood flow during maternal hyperoxygenation. The associated increase in venous return to the left atrium, however, resulted in reversal of the atrial shunt, with no improvement in left ventricular output. The child initially underwent single ventricle palliation with a neonatal hybrid procedure, but following postnatal growth of the left ventricle tolerated conversion to a biventricular circulation at 5 months of age. We conclude that when there is significant restriction of filling or outflow obstruction across the left heart, neither prenatal nor postnatal acute pulmonary vasodilation can augment left ventricular output enough to support a biventricular circulation. Chronic pulmonary vasodilation may stimulate the growth of the left-sided structures allowing biventricular repair, raising the intriguing question of whether chronic maternal oxygen therapy might obviate the need for neonatal single ventricle pallation in the setting of borderline left ventricular hypoplasia.
\end{abstract}

Keywords: Foetal MRI; hypoplastic left heart syndrome; hybrid procedure

Received: 13 June 2014; Accepted: 28 August 2014; First published online: 2 October 2014

A SSESSMENT OF THE ADEQUACY OF THE LEFT ventricle to support a biventricular circulation in newborns with left ventricular hypoplasia remains a critical issue in paediatric cardiology. If possible, biventricular repair is desirable as single ventricle palliation is associated with a reduced life expectancy and increased morbidity. ${ }^{1}$ The inappropriate selection of a biventricular repair in newborns whose left hearts are too small, restrictive, or obstructed results in left atrial hypertension with pulmonary vascular disease, right heart failure, and poor systemic perfusion, leading to poor outcomes. ${ }^{2}$ Various echocardiographic measures are used to aid decision making regarding the correct surgical strategy, ${ }^{3}$ whereas cardiac MRI has been proposed as an adjunct to echocardiography to assess left ventricular

Correspondence to: M. Seed, MD, The Hospital for Sick Children, 555 University Avenue, Toronto, Ontario, Canada M5G 1X8. Tel: 4168137654 x 204067; Fax: 416813 7547; E-mail: mike.seed@sickkids.ca size and output in these cases. ${ }^{4}$ Phase-contrast MRI has also recently been used to measure the distribution of the foetal circulation in normal controls and late gestation foetuses with left-sided $\mathrm{CHD}^{5-7}$ In keeping with the flow theory of cardiac development, foetal MRI has demonstrated reduced oval foramen flow in the setting of diminished growth of left heart structures ${ }^{6,8}$ (Fig 1). On the basis of previous trials of maternal hyperoxygenation in normal foetuses and foetuses with $\mathrm{CHD},{ }^{9-11}$ we hypothesised that venous return to the underfilled left ventricle in this case of borderline left ventricular hypoplasia with atrial septal restriction could be augmented by inducing pulmonary vasodilatation through the administration of maternal oxygen.

\section{Case report}

We present a case of borderline left ventricular hypoplasia diagnosed in foetal life. Foetal echocardiography showed significant ventricular disproportion, mitral 
(a)

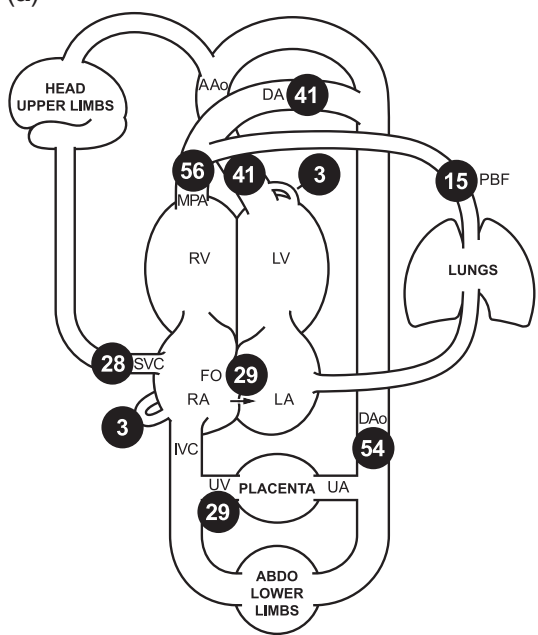

(b)

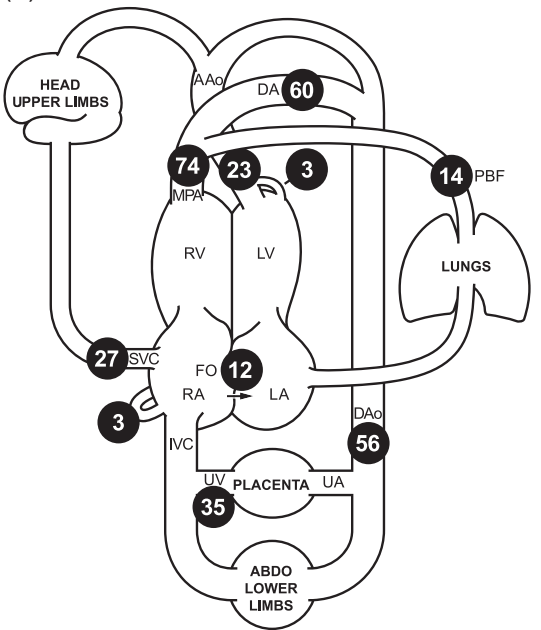

(c)

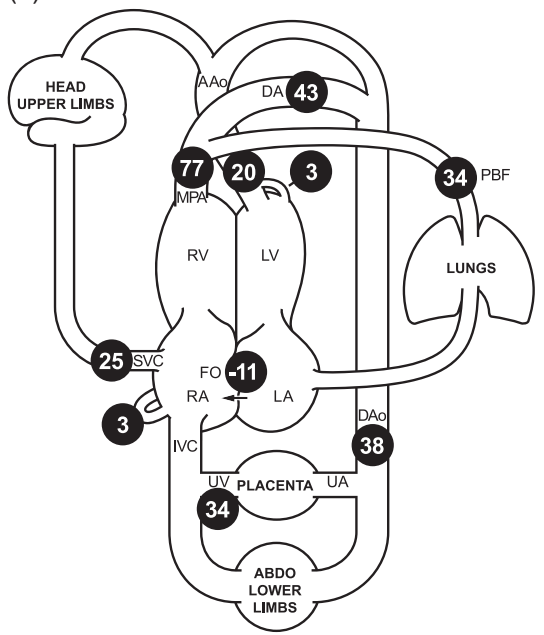

Figure 1.

Cardiac MRI flow distribution in the foetal circulation, shown as mean percentages of the combined ventricular output (CVO) in (a) 40 normal late gestation foetuses, and (b) our case of borderline left ventricular bypoplasia, before maternal byperoxygenation, and (c) following 20 minutes of maternal hyperoxygenation with $70 \%$ oxygen by non-rebreathing mask. Foramen ovale shunt is calculated as the difference between the ascending aorta and pulmonary blood flow. The reported mean percentages of the distribution of CVO required minimal adjustment to conform to a principle of conservation of flow across the foetal circulation, using a published model extrapolated from measured flows using constrained non-linear optimisation ${ }^{7}$. AAo/Dao = ascending/descending aorta; DA =ductus arteriosus; FO = foramen ovale; $M P A=$ main pulmonary artery; $P B F=$ pulmonary blood flow; $R A / L A=$ right/left atrium; $R V / L V=$ right/left ventricle; SVC/ $I V C=$ superior/inferior vena cava; $U A / U V=$ umbilical artery/vein.

valve diameter 6 SDs below the mean, and restrictive right-to-left flow at the oval foramen. The ascending aorta was small, and colour imaging revealed that a proportion of the blood supply to the upper body was being supplied by the right ventricle via the arterial duct, with retrograde flow across the aortic isthmus. Foetal cardiac MRI at 37 weeks' gestation also showed ventricular disproportion (Supplementary Figures S1 and S2). Blood flow measurements made using cine phase-contrast imaging with metric optimised gating ${ }^{5}$ revealed a $50 \%$ reduction in ascending aortic flow compared with normal controls, with a 3:1 ratio of right ventricular to left ventricular output (normal 1.3:1). Pulmonary blood flow was normal. Oval foramen flow was significantly lower than the normal foetal mean (Fig 1), consistent with possible flow restriction across the atrial septum.

We hypothesised that maternal hyperoxygenation would induce pulmonary vasodilation and increase filling of the left ventricle. However, whereas maternal hyperoxygenation (20 minutes of $70 \%$ oxygen by nonrebreathing mask) caused a nearly twofold increase in pulmonary blood flow by MRI (Fig 1), the increased venous return did not augment the ascending aortic outflow. Instead, there was a reversal of atrial shunting, suggesting that valvar obstruction and ventricular hypoplasia were restricting flow across the left heart.

The child was born at term, with birthweight $2.89 \mathrm{~kg}$, oxygen saturations $98-100 \%$ preductally and $78-84 \%$ postductally. Echocardiography demonstrated a nearly apex-forming left ventricle and small mitral (annulus $7.0 \mathrm{~mm}, \mathrm{z}$ score -4.3 ) and aortic (annulus $4.8 \mathrm{~mm}, \mathrm{z}$ score -4.6 ) valves. Prostaglandin E1 treatment was started to ensure systemic perfusion. Postnatal MRIs (Fig 2) showed an indexed left ventricular enddiastolic volume of $27 \mathrm{ml} / \mathrm{m}^{2}$ on the 1st day of life and $35 \mathrm{ml} / \mathrm{m}^{2}$ at 1 week, a gradual increase in pulmonary blood flow, yet no associated increase in left ventricular output. Notwithstanding, prostaglandin treatment was discontinued to assess whether a biventricular circulation was feasible following closure of the arterial duct, although this resulted in poor systemic perfusion with metabolic deterioration. At 9 days of life, the child underwent a hybrid procedure, consisting of bilateral pulmonary artery banding and ductal stenting.

Cardiac MRI at 4 months of age demonstrated further growth of the left ventricle, with a left ventricular end-diastolic volume index of $62 \mathrm{ml} / \mathrm{m}^{2}$, and ascending aortic flow in excess of $3 \mathrm{~L} / \mathrm{minute} / \mathrm{m}^{2}$. Echocardiography showed no inflow or outflow obstruction and mitral valve diameter 2.8 SDs below the mean. In view of the encouraging investigations, the child underwent elective biventricular repair at 5 months of age, including arch reconstruction, duct ligation, and atrial septal defect creation. She made an uneventful recovery and is clinically well, gaining weight appropriately, on no cardiac medications 18 months later. She has mild residual mitral and aortic valvar stenosis, but there is no evidence of pulmonary hypertension. 
(a)

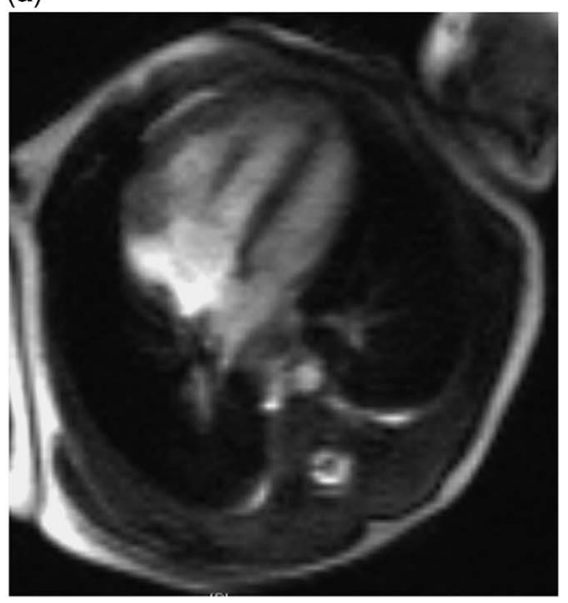

(b)

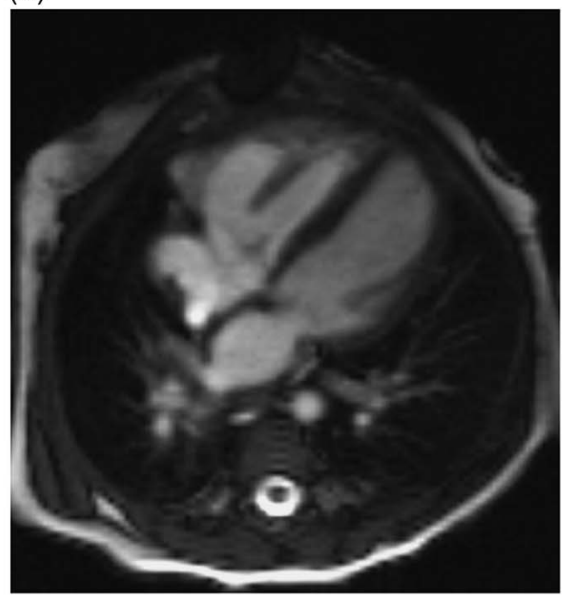

Figure 2 .

Postnatal cardiac MRI images of the four-chamber view. (a) At day 1 of life, the left ventricle appears small and has an indexed left ventricular end-diastolic volume (LVEDVi) of $27 \mathrm{ml} / \mathrm{m}^{2}$, and measured ascending aortic flow is $1.57 \mathrm{~L} / \mathrm{minute}^{2} \mathrm{~m}^{2}$. (b) At $4.5 \mathrm{months}$ of life, subsequent to a neonatal bybrid procedure of bilateral pulmonary artery banding and arterial ductal stenting, the left ventricular size appears normal, with an LVEDVi of $62 \mathrm{ml} / \mathrm{m}^{2}$, and ascending aortic flow is $3.14 \mathrm{~L} /$ minute $/ \mathrm{m}^{2}$.

\section{Discussion}

The pathogenesis of hypoplastic left heart syndrome, ranging from the borderline left ventricle to complete aortic and mitral atresia, is not fully clear. It is likely multi-factorial, relating to genetic and anatomic factors, with restricted flow across the foetal oval foramen in the setting of low pulmonary blood flow, also impairing the development of the left-sided structures. ${ }^{1}$ The possibility of finding an option to aid the antenatal development of the borderline ventricle is extremely engaging. Furthermore, decision making regarding the adequacy of the borderline left ventricle for a biventricular repair is complex, and an improved understanding of the physiology and natural history of patients with this spectrum of abnormalities is desirable. Pulmonary vasodilation in response to maternal hyperoxygenation has been described in foetal sheep 8 and shown in human foetuses by echocardiography. ${ }^{9-11}$ As far as we are aware, this account represents the first report of an increase in pulmonary blood flow in response to maternal hyperoxygenation by foetal cardiac MRI.

Thomas Kohl has proposed maternal hyperoxygenation as a treatment for achieving growth of underdeveloped left heart structures ${ }^{9}$ and reported encouraging results in 13 late gestation foetuses, although with no control group. Importantly, oxygenation did not cause ill effects to the foetuses such as ductal constriction or cardiac dysfunction, or mothers, for example, pulmonary oedema, in keeping with previous evidence of the acute safety of maternal hyperoxygenation ${ }^{11}$ and reversibility of its effects on foetal circulation. ${ }^{10}$ The safety of chronic maternal hyperoxygenation in the setting of intrauterine growth restriction has been addressed by a Cochrane Review, ${ }^{12}$ which concluded that, although three randomised controlled trials showed no evidence of adverse effects from maternal oxygen therapy, there was a potential for harm from maternal oxygen therapy resulting from reduced placental blood flow based on animal models.

In our case, maternal hyperoxygenation led to a clear increase in foetal pulmonary blood flow, but no increase in left ventricular output. These findings suggest impaired left ventricular filling owing to restrictive left ventricular physiology and/or anatomical obstruction. However, it is interesting to consider whether a more prolonged exposure to maternal oxygenation could have improved left heart growth in utero, potentially allowing a biventricular repair in the neonatal period, just as improved left ventricular filling via the pulmonary circulation in this patient and others reported in the literature resulted in the growth of left heart structures after birth. ${ }^{13}$

\section{Financial Support}

This research received no specific grant from any funding agency, commercial, or not-for-profit sectors.

\section{Conflicts of Interest}

None.

\section{Ethical Standards}

The authors assert that all work reported complies with the ethical standards of the Helsinki convention, 
and consent for publication has been granted by the patient's family.

\section{Supplementary material}

To view supplementary material for this article, please visit http://dx.doi.org/10.1017/S1047951114001802

\section{References}

1. Feinstein JA, Benson DW, Dubin AM, et al. Hypoplastic left heart syndrome: current considerations and expectations. J Am Coll Cardiol 2012; 59 (Suppl 1): S1-42.

2. Tchervenkov CI, Tahta SA, Jutras LC, Beland MJ. Biventricular repair in neonates with hypoplastic left heart complex. Ann Thorac Surg 1998; 66: 1350-1357.

3. Colan SD, McElhinney DB, Crawford EC, Keane JF, Lock JE. Validation and re-evaluation of a discriminant model predicting anatomic suitability for biventricular repair in neonates with aortic stenosis. J Am Coll Cardiol 2006; 47: 1858-1865.

4. Grosse-Wortmann L, Yun TJ, Al-Radi O, et al. Borderline hypoplasia of the left ventricle in neonates: insights for decision-making from functional assessment with magnetic resonance imaging. J Thorac Cardiovasc Surg 2008; 136: 1429-1436.

5. Seed M, van Amerom JF, Yoo SJ, et al. Feasibility of quantification of the distribution of blood flow in the normal human fetal circulation using CMR: a cross-sectional study. J Cardiovasc Magn Reson 2012; 14: 79 .
6. Al Nafisi B, van Amerom JF, Forsey J, et al. Fetal circulation in leftsided congenital heart disease measured by cardiovascular magnetic resonance: a case-control study. J Cardiovasc Magn Reson 2013; 15: 65.

7. Prsa M, Sun L, van Amerom J, et al. Reference ranges of blood flow in the major vessels of the normal human fetal circulation at term by phase-contrast magnetic resonance imaging. Circ Cardiovasc Imaging 2014; 7: 663-670.

8. Rudolph AM. Congenital Diseases of the Heart: ClinicalPhysiological Considerations, 3rd edn. Wiley-Blackwell, Chichester, UK, 2009.

9. Kohl T. Chronic intermittent materno-fetal hyperoxygenation in late gestation may improve on hypoplastic cardiovascular structures associated with cardiac malformations in human fetuses. Pediatr Cardiol 2010; 31: 250-263.

10. Rasanen J, Wood DC, Debbs RH, Cohen J, Weiner S, Huhta JC. Reactivity of the human fetal pulmonary circulation to maternal hyperoxygenation increases during the second half of pregnancy: a randomized study. Circulation 1998; 97: 257-262.

11. Szwast A, Tian Z, McCann M, Donaghue D, Rychik J. Vasoreactive response to maternal hyperoxygenation in the fetus with hypoplastic left heart syndrome. Circ Cardiovasc Imaging 2010; 3 : 172-178.

12. Say L, Gülmezoglu AM, Hofmeyr GJ. Maternal oxygen administration for suspected impaired fetal growth. Cochrane Database Syst Rev 2009; 1: CD000137.

13. Ballard G, Tibby S, Miller O, et al. Growth of left heart structures following the hybrid procedure for borderline hypoplastic left heart. Eur J Echo 2010; 11: 870-874. 